\title{
TEMOS QUE PEGAR? POKÉMON GO E AS INTERFACES ENTRE MOVIMENTO, JOGOS DIGITAIS E EDUCAÇÃO
}

\section{RESUMO}

Este ensaio problematiza as relações entre jogos digitais, educação e movimento por intermédio do game Pokémon Go e à luz de tendências emergentes no âmbito da aprendizagem móvel e da indústria do entretenimento. Apesar da potencialidade demonstrada por títulos como Pokémon Go, o nicho dos games de realidade aumentada ainda apresenta entraves relativos à plena mobilização de suas capacidades formativas e recreativas. Entre os desafios mais prementes suscitados pelos referidos jogos, destacam-se a qualificação e diversificação das experiências motoras que propiciam, juntamente com a desvinculação de modelos de negócios subordinados a interesses estritamente econômicos.

Palavras-chave: Educação. Jogos Digitais. Pokémon Go. Aprendizagem Móvel.

1 Doutor em Educação. Professora da Universidade Federal do Oeste do Pará (UFOPA). Santarém/Pará, Brasil. E-mail: gilsu05@gmail.com 


\title{
GOTTA CATCH'EM ALL? POKEMON GO AND THE INTERFACES BETWEEN MOVIMENT, GAMES AND EDUCATION
}

\begin{abstract}
This essay discusses the relationship between digital games, education and movement through Pokemon Go and in the light of emerging trends in mobile learning and in the entertainment industry.Despite the potential demonstrated by titles like Pokemon Go, the augmented reality games niche also presents obstacles for the full mobilization of their educational and recreational skills.Among the most urgent challenges posed by these games, we highlight the improvement and diversification of motor experiences provided by them, besides its untying of business models subordinated to purely economic interests.
\end{abstract}

Keywords: Education. Digital Games. Pokemon Go. Mobile Learning.

\section{TENEMOS QUE ATRAPARLOS? POKEMON GO Y LAS INTERFACES ENTRE MOVIMIENTO, JUEGOS Y EDUCACIÓN}

\section{RESUMEN}

En este ensayo se analizalarelación entre losjuegosdigitales, laeducación y elmovimiento a través deljuegoPokemon Go y a la luz de lasnuevastendenciasenlaaprendizajemóvil y laindustriadelentretenimiento. A pesar del potencial demostrado por títulos como Pokemon Go, el segmento de losjuegos de realidad aumentada también presenta obstáculos para lamovilización completa de su potencial educativo y recreativo. Entre losdesafíos más urgentes que planteanestosjuegos, destacamos lamejora y diversificación de lasexperiencias motoras que proporcionan, junto conladesvinculación de los modelos de negocios subordinados a intereses puramente económicos.

Palabras clave: Educación. Juegos Digitales. Pokemon Go. Aprendizaje Móvil. 


\section{INTRODUÇÃO}

Desde o seu lançamento, o game Pokémon Go se afirmou como fenômeno de popularidade que se generalizou em diferentes países, grupos sociais e faixas etárias.A despeito do gradual esmorecimento do entusiasmo em torno do jogo ${ }^{2}$, essa notoriedade encontra ressonância na expressiva quebra de recordes perpetrada pelo título. Antes de completar um mês de existência, já havia superado marcas estratégicas no segmento dos games mobile, como a de jogo mais baixado, de maior receita bruta e de maior número de rankings internacionais em número de downloads e receita ${ }^{3}$. Estes são apenas alguns dos sintomas da febre que levou Pokémon Go a se tornar objeto de interesse em âmbitos variados.

Considerado uma iniciativa pioneira no que diz respeito ao uso de tecnologias móveis, Pokémon Go foi recebido com euforia não apenas pela indústria do entretenimento, mas também por ramos de atividade diversificados, como o lazer, a saúde e a educação. Sobre esta, muito tem se especulado sobreas possíveis apropriações do game em processos de ensino-aprendizagem formais e informais. No que diz respeito às transformações cotidianas, também têm sido discutidos os supostos impactos positivos gerados pelo jogo no que tange ao estímulo de hábitos e estilos de vida saudáveis através da prática de atividades físicas. Seja como for, toda agitação gerada por e em torno de Pokémon Goé um forte indicativo de que este servirá como inspiração para novos projetos similares ${ }^{4}$, fato que acentua a pertinência de leituras e análises mais aprofundadas sobre o jogo.

Para além do tom celebratório com o qual foiamplamente acolhido, é necessário reconhecer que Pokémon Go se apresenta como um mote prenhe de questionamentos para o campo acadêmico.Entre os principais desafios em seu horizonte,está a demanda por maiores esclarecimentos acerca dos novos arranjos e conexões entre tecnologias digitais e atividades lúdicas. Diante disso, o objetivo do presente ensaio é justamente discutir e problematizar as intercessões entre jogos (digitais), movimento e educação por intermédio do game Pokémon Go, identificando e refletindo sobre suas potencialidades e pontos de tensão sob a óticaformativa. No contexto do presente trabalho, o game em questão serve menos como um fim e mais como um meio, ou seja, um facilitador a serviço da explicitação de conceitos e princípios emergentes no cenário da cultura digital. Para alcançar essa meta, foi traçado o seguinte itinerário reflexivo:a) apresentaçãodos fundamentos da aprendizagem móvel e dos sistemas de realidade aumentada; b) descriçãodas principais mecânicas de jogo em Pokémon Go, bem como dos comportamentos por elas suscitados; c) ponderaçõesacercados riscos e oportunidadesinerentesao jogo no que tange às suas articulações com o movimento e a educação.

2 http://www.refinery29.com/2016/08/121845/pokemon-go-popularity-decrease

3 http://www.techtudo.com.br/noticias/noticia/2016/08/pokemon-go-quebrou-cinco-recordes-no-livro-guinnessconheca-todos.html

4 https://hipermediaciones.com/2016/08/19/entre-pokemon-go-no-mans-sky-y-oculus-el-futuro-delentretenimiento-interactivo-i/ 


\title{
MOBILE LEARNING E REALIDADE AUMENTADA
}

Em linhas gerais, o conceito de aprendizagem móvel não é universal e nem isento de discordâncias. Ainda assim, este costuma ser entendido como uma modalidade educativa que opera na confluência entre diferentes tecnologias de informação e comunicação e que tem como lastro todo o conjunto de mídias móveis dotadas de acesso a redes sem fio. Entre os dispositivos de maior destaque neste âmbito, estão os smartphones, tablets e PDA's. Não obstante, essa questão gera certa controvérsia, uma vez que, ao ser entendido de modo amplo, o mobile learning pode abranger um vasto espectro de recursos midiáticos.

No entendimento de Martin et al (2015), experiências educacionais sob a égide da aprendizagem móvel podem ser engendradas com a ajuda de tecnologias situadas em diferentes esferas de sofisticação. Esse campo de abrangência acolhe tanto recursos analógicos de pouca ou nenhumabase eletrônica (placas, mapas impressos e envelopes contendo notas), quanto dispositivos computadorizados como notebooks, câmeras e gravadores. Atualmente, as principais iniciativas em termos de aprendizagem móvel têm se tornado sinônimos do que existe de mais avançado e ao mesmo tempo popular em termos de mídia digital. Nesta categoria, são comuns as menções a dispositivos inteligentes, conexões $3 G$ e 4G, baterias externas portáteis, áudio e vídeo digitais, hubs de wi-fi móveis e recursos de geolocalização (GPS).

Em outro viés, também é corrente a ideia de que o mobile learning não deve ser definido pelo tipo de aporte tecnológico que emprega. Eric Klopfer (2011) é um dos estudiosos que se apoiam nessa visão. Para ele,ao invés de operar em função das tecnologias em si, a aprendizagem móvel e sua definição devemse voltar às suas particularidades no tocante à configuração dos vínculos entre o usuário-aprendiz, a tecnologia e o ambiente:

\begin{abstract}
Eu recentemente passei por um carrinho de compras com aproximadamente meia dúzia de computadores de mesa com monitores de tubo gigantes. O carrinho tinha uma placa grande com uma etiqueta dizendo: "laboratório móvel de informática". Isso não é mobilidade. Laptops também não podem ser considerados móveis nesse contexto. Mobilidade exige a habilidade de usar casualmente um dispositivo em movimento - sem se sentar. Embora possa parecer arbitrário, isso é importante na medida em que influencia a maneira como utilizamos esses aparelhos. Eles não são focados apenas em sessões longas, mas também podem ser utilizados de modo breve tomando apenas alguns segundos em uma atividade outra (ou não-relacionada) (KLOPFER, 2011, p. 6, tradução nossa).
\end{abstract}

As tecnologias móveis compõem um dos nichos mais jovens no âmbito das mídias digitais, fato que explica o alto grau de experimentalismo presente em seus usos e apropriações mais recentes. Ainda assim, em termos de caracterização, Klopfer (2011) apresenta um conjunto de fundamentos que, sob a sua ótica, expressam as principais qualidades dos dispositivos móveis para os processos de ensino-aprendizagem. São eles:

- Portabilidade: possibilidade de carregar um computador - aparelho capaz de produzir e processar informações - para diferentes espaços e com elese mover livremente; 
- Interatividade social: possibilidade de intercambiardados e de colaborar com outras pessoas cara a cara;

- Sensibilidade ao contexto: possibilidade de recolher dados únicos do atual ambiente, local e tempo, incluindo tanto informações reais quanto simuladas;

- Conectividade: possibilidadede conectar dispositivos portáteis a tecnologias que coletam informações, a outros portáteis e a redes comuns que criam um legítimo contexto compartilhado;

- Individualidade: possibilidade de oferecer uma sustentação única, isto é, customizada, aos modos de compreensão e investigação individuais.

Impulsionada pelo advento, aprimoramento e popularização das mídias digitais móveis, a implosão das fronteiras entre tempo e espaço $0^{5}$ pode ser considerada um processo amplo que tem gerado inúmeros desdobramentos, entre os quais é pertinente sublinhar a ascensão de um novo segmento no contexto das tecnologias de informação e comunicação: a realidade aumentada. Em geral, os objetivos dos projetos sob essa flâmula envolvem a melhoria e o aperfeiçoamentode nossa percepção do ambiente mediante tecnologias de deteç̧ão, computação e exibição. Embora esse conceito abarque todos os sentidos humanos, a maior parte das iniciativas baseadas em realidade aumentada tem se voltado exclusivamente à visão e, em menor medida, à audição.

Tendo como parâmetro os referidos projetos inscritos no plano visual, Olwan (2009) sugere que os sistemas de realidade aumentada podem ser identificados a partir de três critérios distintos, a saber: 1) combinação entre real e virtual - exigem tecnologias de exibição que possibilitam aos usuários ver informações virtuais e reais de modo articulado; 2) registro em $3 \mathrm{D}$ - dependem do acoplamento íntimo entre o real e o virtual baseado em suas relações geométricas; 3 ) interatividade em tempo real - devem operar em ritmo síncrono de entradas e saídas, garantindouma abertura à participação do usuário por intermédio da sobreposição de informações em tempo real. As aplicações dos sistemas de realidade aumentada podem ser bastante variadas: de atividades altamente especializadas, como procedimentos médicos/cirúrgicos, até práticas de lazer e entretenimento, como aquelas dirigidas aos jogos digitais.

Um dos exemplos é o Ingress ${ }^{6}$, game baseado em localização lançado em 2013, cujo objetivo envolve a criação e ohackeamento de portais em sítios específicos do mundo real. Nesse caso, os jogadores se dividem em dois times diferentes, escolhidos individualmente já no primeiro acesso ao game, disputando a posse de cada um dos portais espalhados por diferentes locais da cidade. Jogado em celulares dotados de tecnologias de geolocalização, câmeras e acesso à internet, Ingress é considerado uma experiência lúdica pioneira em termos de uso da realidade aumentada. Por outro lado, apesar de ter acumulado alguma notabilidade na época de seu lançamento, o game não foi capaz de estimular uma generalizaçãodo uso e da exploração de tais sistemas no cotidiano. Trata-se de uma tarefa

5 (BAUMAN, 2001).

6 Trailer disponível em: https://www.youtube.com/watch?v=Ss-Z-QjFUio 
que parece ter sido legada a um de seus mais recentes sucessores "espirituais": o game Pokémon Go - objeto do próximo tópico.

\section{POKEMON GO: O MOVIMENTO COMO FORÇA CARTOGRÁFICA}

Desenvolvido pela Niantic Inc. ${ }^{7}$ em parceria com a Nintendo ${ }^{8}$ e a The PokemonCompany ${ }^{9}$,Pokémon Go consiste num game de realidade aumentada e baseado em localização criado para smartphones e disponível para as plataformas Android e iOS. Lançado no ano de 2016, o game já é considerado uma das maiores e mais populares experiências de entretenimento digital em mídia móvel da história, sendo amplamente reverenciado (e também questionado) pelos diversos impactos culturais gerados no cotidiano das diferentes regiões em que se faz presente.

Em certa medida, o misto de entusiasmo e apreensão que ronda Pokémon Go é algo que pode ser expresso pelos diversos acontecimentos envolvendo seus jogadores, fatos estes que têm sido ostensivamente noticiados em diferentes veículos de comunicação. Dentre feitos e incidentes mais notórios, é possível destacar os jogadores que, enquanto jogavam foram alvejados com ovos e baldes d'água por moradores incomodados com o alvoroço e a agitação em frente às suas residências; foram apunhalados e (mesmo feridos) continuaram jogando; postaram fotos capturando pokémonsnas trincheiras em meio à guerra contra o Estado Islâmico; foram assaltados por delinquentes que se utilizaram do game como isca para atrair vítimas em potencial; pularam cercas para dentro de zoológicos, invadindo espaços reservados a animais perigosos como tigres; capturaram pokémons durante a realização de um parto, na própria sala de cirurgia; invadiram postos policiais; caíram de penhascos; foram atropelados ou bateram em viaturas da polícia ${ }^{10}$. Evidentemente, este é apenas um breve resumo das principais notícias e fatos (incomuns) envolvendo o game poucas semanas após o seu lançamento.

Em outro viés, Pokémon Gotambém tem chamado atenção por conta de alguns impactos aparentemente benéficos decorrentes de sua popularização, entre os quais, sobressai o estimulo à realização de atividades físicas. Seguindo a premissa elementar do universo ficcional da série, a tarefa primária do jogo consiste em caçarpokémons, isto é, monstros dotados de poderes e habilidades especiais. Essa é a atividade basilar que alimenta as demais vivências proporcionadas pelo game. Para realizá-la, é necessário transitar por espaços do mundo real, os quais são diagramados em função de mapas presentes em sistemas degeolocalização, como o Google Maps. Sempre que um pokémon está próximo, um

7 https://www.nianticlabs.com/

8 http://www.nintendo.com/

9 http://www.pokemon.com/br/

10 Essas informações foram retiradas do vídeo produzido pelo canal Watchmojo, intitulado "Top 10 craziestthingsthathappenedwhileplayingPokemon Go" e disponível em: https://www.youtube.com/watch?v= $3 q y f a z S q 5 s$ 
alerta vibratório é emitido pelo celular, permitindo que ojogador escolha se vai capturá-lo ou não (IMAGEM 1). É no momento da captura que ocorre o uso do mecanismo de realidade aumentada: por intermédio da câmera acoplada ao dispositivo móvel, o game capta informações (imagens em movimento) do ambiente real, mesclando-as com um modelo tridimensional animado do pokémon encontrado, o qual é exibido no display em tempo real. Para domesticar a criatura, o jogador precisa deslizar a pokebola localizada na parte inferior da tela em direção ao pokémon encontrado.

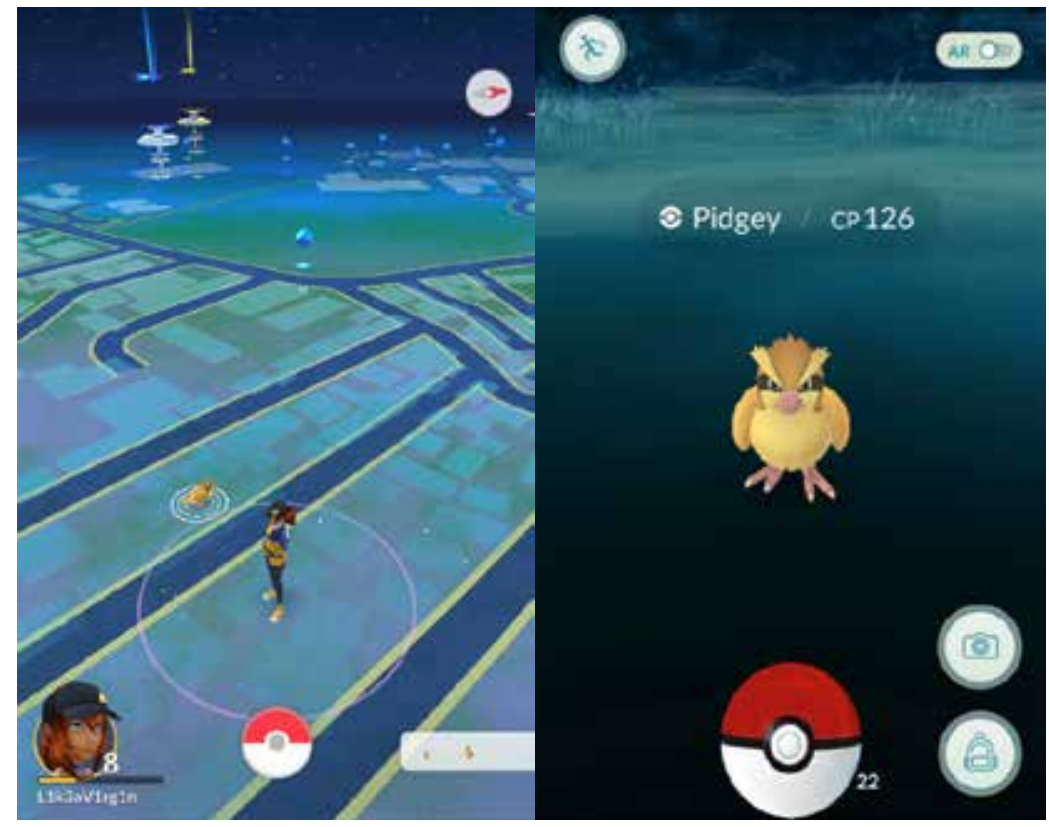

Imagem 1 - À esquerda, exploração e caça de pokémons; à direita, momento da captura Fonte - Dados da pesquisa

De fato, Pokémon Go impõe que o jogador explore o mundo à sua volta como condição para que este avance no game. Para isso, além das mecânicas ${ }^{11}$ de jogo ligadas à caça de pokémons, a obtenção e administração de recursos é uma parte essencial da experiência. Alguns dos itens essenciais para a execução de atividades primárias do jogo são limitados. Esse é caso das pokebolas, que, ao se esgotarem, impedem que o jogador possa capturar qualquer outro pokémon. Nesse caso,existem ao menos duas maneiras de obtê-las: 1) subindo de nível; e 2) visitando as pokestops (IMAGEM 2).Na primeira, elas

11 Podem ser definidas como microssistemas de regras criados para gerar dinâmicas específicas, isto é, respostas comportamentais por parte dos jogadores (HUNICKE; LEBLANC; ZUBEK, 2004). 
vêm sob a forma de prêmios recebidos ao bater certas marcas de pontos de experiência ${ }^{12}$. Já na segunda, são adquiridas em locais específicos da cidade - quase sempre pontos turísticos, históricos, artísticos ou espaços públicos com grande circulação de pessoas -, aos quais o jogador deve se dirigir sempre que o seu estoque chegar ao fim. Em ambas as situações, fica explícito alguns dos modospelos quais as mecânicas de jogo estimulam a exploração e a descoberta de novos ambientes, fazendo com que o jogador saia de casa e ande por ruas, avenidas, praças e demais contextos públicos, na tentativa de alcançar os objetivos fixados pelo game.

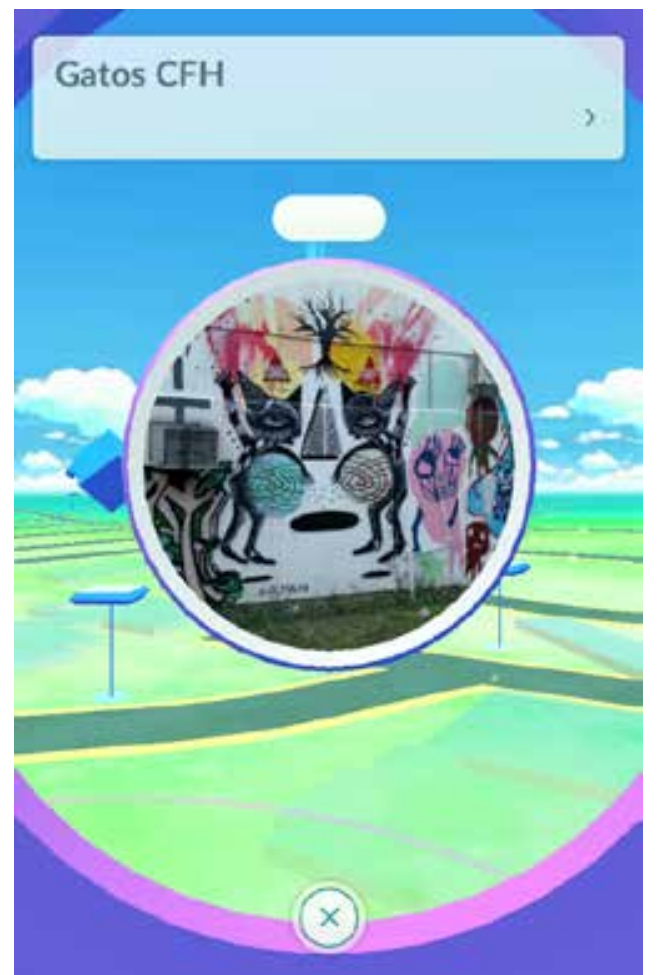

Imagem 2 - Pokestop

Fonte - Dados da pesquisa

12 É importante ressaltar que Pokémon Go é estruturado a partir de mecânicas de RPG, as quais usualmente se organizam com base em sistemas de experiência. A experiência corresponde a uma unidade de pontuação que tem por função recompensar o jogador pelas missões e tarefas cumpridas, mais precisamente aquelas que são consideradas significativas para os sistemas do jogo. Em games do gênero, o jogador controla personagens que, ao atingirem somas predeterminadas de experiência, alcançam um novo nível e com isso ganham recompensas variadas (itens, habilidades, atributos e etc.). Em Pokémon Go, o modo mais comum de obter pontos de experiência é através da captura de pokémons. 
Outro destaque de Pokémon Go diz respeito não apenas às maneirascomo os jogadores são intimados a se deslocarem, mas também à importância dada, em casos muito específicos, àpermanênciaem instâncias predeterminadas. Como já foi dito, as pokestops são pontos fixos onde o jogador pode reabastecer seu inventário com recursos essenciais à sua jornada. Entretanto, a disponibilidade dos itens distribuídos nas pokestops é cuidadosamente calculada, de modo que são disponibilizadas entre três e cinco unidades aleatórias por vez. Após coletar os espólios, o jogador deve aguardar ao menos cinco minutos para que a pokestop seja novamente ativada e permita a ele obter mais itens. É pouco provável que um jogador obtenha tudo aquilo que necessita na primeira tentativa. Por essa razão, todos aqueles que se dirigem a uma pokestop tendem a nela estacionar por algum tempo. Trata-se de uma mecânica baseada em tempo que, entre outras metas,busca favorecer a interação dos jogadores que se dirigem às pokestops: se há a necessidade de aguardar a liberação dos itens desejados, o contato (direto) com outros jogadores é uma maneira contingente de reduzir o tédio da espera.

A socialização entre jogadores também é estimulada por intermédio de dinâmicas de cooperação e competição. Ao chegar ao nível cinco, o jogador deve escolher um dos três times presentes no game: Valor, Mystice Instict(IMAGEM3). Cada um deles tem como emblema um pokémon lendário (Moltres, Articuno e Zapdos) e um(a) treinador(a)-guia (Candela, Blanche e Spark). A função dos times está diretamente ligada aos ginásios que, assim como as pokestops, estão distribuídos por pontos fixos da cidade e são objetos de disputa entre os jogadores. Caso se encontre vazio, o ginásio pode ser ocupado por um jogador que, por sua vez, nele deve deixar um de seus pokémons, tendo em vista as situações em que um outro jogador tente tomar posse do referido ponto através de uma batalha. A disputa por um ginásio é permitida apenas caso este pertença a um treinador de uma equipe adversária. Não obstante, se pertencer a um indivíduo do mesmo time, o jogador pode nele permanecer usufruindo de benefícios semelhantes aos das pokestops: além da obtenção de itens especiais, pode-se também treinar seus pokémons, aumentando sua capacidade de combate. Além disso, o ginásio, assim como os jogadores, pode aumentar de nível conforme o indivíduo que detém a sua posse vença os desafiantes que provavelmente tentarão destituí-lo de sua hegemonia.Ao subir de nível, o ginásio abre uma nova vaga para que mais um pokémon pertencente a um treinador da mesma equipe do atual líder possa defender o território.

Em linhas gerais, essas são as principais mecânicas de jogo presentes em Pokémon Go. Cada uma tem funções distintas no que diz respeito à promoção de comportamentos e ações particulares por parte dos jogadores. No entanto, a popularidade do jogo não se deve apenas às escolhas de design expressas em suas experiências. Em certa medida, esse sucesso está associado a uma série de aspectos estruturantes da indústria do entretenimento (digital), os quais podem não ser inteiramente transparentes à primeira vista, assim como os méritos e obstáculos no que diz respeito à dimensão educativa - assuntos do tópico a seguir. 


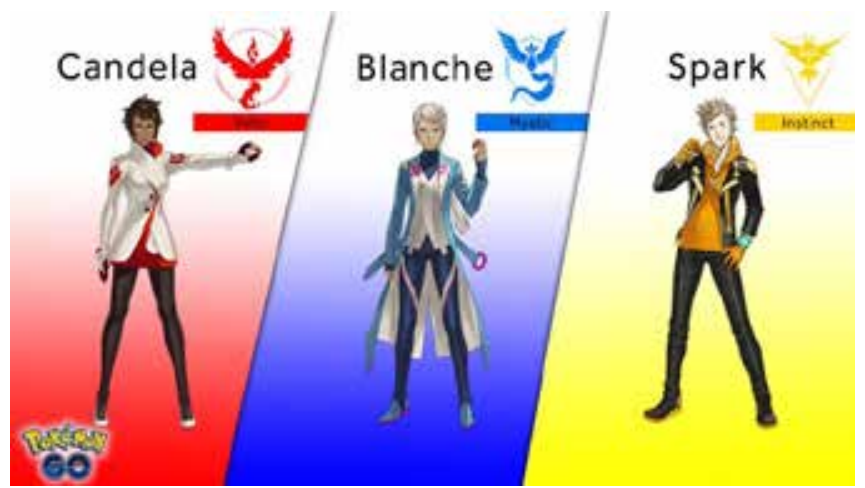

Imagem 3 - Times e Treinadores-líderes

Fonte - Techtudo - http://www.techtudo.com.br/noticias/noticia/2016/07/ pokemon-go-revela-lideres-dos-times-e-confirma-centros-pokemon.html

\section{ENTRE A POTÊNCIA E O ENGODO}

Um dos principais fatores envolvidos no aparente êxito de Pokémon Go é a sua filiação a uma franquia icônica em termos de pioneirismo no âmbito dos conteúdos transmidiáticos ${ }^{13}$.Criada por SatoshiTajiri, a série surgiu em 1996 com os games PokémonRed e Blue, ambos lançados para o portátilGameboy Color.Desde então, foram desenvolvidos dezenas de outros games da marca para múltiplas plataformas, com destaque para aquelas que pertencem à Nintendo, detentora de todos os seus direitos de comercialização. Além dos jogos, Pokémon também adquiriu notoriedade mundial por conta de sua série animada, a qual, no ano de 2016 chegou à sua 19a temporada. Essa longevidade parece alimentaro caráter ubíquo do universode Pokémon no imaginário social. Trata-se de um fenômenomulti e intergeracional, pois além de atingir a diferentes faixas etárias (crianças, adultos e idosos), também estimula a interação entre todos esses segmentos ${ }^{14}$.

Outro aspecto digno de menção é a congruência entre o universo ficcional da série e os desafios propostos por Pokémon Go. Um dos jargões que perpassa todos os conteúdos da franquia é a premissa do(a) jovem que viaja o mundo caçandopokémons e participando debatalhas e competições oficiais contra outros treinadores.Sob o ponto de vista das mecânicas de jogo, a maior parcela dos games da série sempre propuseram tarefas alinhadas a essas premissas. Contudo, a plena realização de tais missões sempre se manteve represada pelos limites técnicos inerentes às plataformas de jogo convencionais - quase sempre consoles e aparelhos portáteis off-line. Por outro lado, Pokémon Go

13 (SCOLARI, 2013).

14 É o caso de pais que não conhecem a série ouo jogo,mas que estão acompanhando as andanças dos filhos e vice-versa: http://g1.globo.com/sp/mogi-das-cruzes-suzano/noticia/2016/08/pais-aproveitam-pokemon-go-parapassar-mais-tempo-com-filhos.html 
combina os personagens e cenários canônicos da série, com um conjunto de tecnologias capazesde expressar de modo mais fiel tudo aquilo que se espera que o jogador execute. A combinação de geolocalização, realidade aumentada, telas sensíveis ao toque, acesso a redes $3 \mathrm{G} / 4 \mathrm{G}$ e pedômetros, criou uma interface mimética ${ }^{15}$, isto é, tornou a atividade e os gestos físicos realizados no mundo real compatíveis às ações lúdico-ficcionais realizadas no contexto do jogo (JUUL, 2010). A relação simbiótica entre narrativas da ficção populares e os recursos midiático-computacionais presentes em tecnologias móveis de amplo acesso se revela um fator determinante no processo de imersão e, por consequência, de sedução dos jogadores.

Sob o ponto de vista educacional, convém demarcar ainda os papéiscumpridos pelo movimento não apenas sob a ótica das mídias e aprendizagens móveis, mas também na perspectiva da corporeidade. Isso implica em superar a ideia (ainda corrente) de que a essência do movimento corporal se esgota em sua faceta físico-biológica, isto é, de que este resume a meras contrações musculares e que suasfunções são tão somente a queima de calorias e a melhoria de capacidades cardiorrespiratórias.

Distante dessa visão, o movimento humano deve ser compreendido como um fenômeno multidimensional, constituindo-se como objeto de investigação abordado em diferentes disciplinas e áreas do conhecimento. Em meio a essa pluralidade, destaca-se a concepção do se-movimentar humano, enfoque inspirado na filosofia fenomenológica e que busca afirmar a relação dialógica existente entre o sujeito (que se move) e o mundo (KUNZ, 2005). Sob este prisma, o cerne do movimento está no ser que desempenha uma ação e não no gesto reproduzido em si, o qual resulta da confluência dos seguintes elementos: 1) um sujeito: aquele de quem parte a realização da ação; 2) uma situação: abrange tanto ambientes físicos quanto contextos socioculturais; 3) umsignificado: princípio motivadore ao mesmo tempo resultante do movimento realizado. Mas afinal, o que isso nos diz sobre Pokémon Go?

O jogo é um elemento da cultura queusualmente se manifesta sob aforma de diversas atividades lúdicas, as quais acionam pessoas, lugares e objetos de modos particulares. Resumidamente, podemos defini-lo como um intervalo na vida cotidiana, mais precisamente, como uma suspensão sempre temporária dos modos de ação e pensamento que vigoram no dia-a-dia. Sob a ótica do se-movimentar humano, o jogo pode ser considerado uma situação em que certos significados são colocados em circulação ou apenas reconfigurados, processos estes que alteram de modo sensível os sentidos subjacentes às ações motoras do sujeito. Em Pokémon Go, o caminhar pela cidade, esforço que habitualmente é encarado de modo literal e pragmático - uma maneira de chegar a algum lugar ou de produzir efeitos positivos sobre o corpo, por exemplo -, é absorvido pela teatralidade inerente ao universo narrativo do game. Ao abandonar sua identidade primeira, tornando-se um treinador pokémon, o sujeito atribui novas intencionalidades ao seu se-movimentar, as quais podem

15 Para Juul (2010), as interfaces miméticas fazem parte de um filão emergente na indústria do entretenimento, podendo ser exemplificadas por meio de séries como Dance DanceRevolution e GuitarHero, além de consoles e acessórios como Nintendo Wii e Kinect. 
produzir novos modos de apropriação do mundoe de nele imprimir a sua presença. Diante disso, o que difere Pokémon Go dos jogos (digitais e não-digitais) que o antecederam?

Cunhada por Johann Huizinga ${ }^{16}$, a noção de círculo mágico é uma das peças-chave na constelação conceitual do jogo. Podemos entendê-la como uma forma de demarcar o espaço-tempo em que essa atividade acontece, bem como uma maneira de sublinhar a separação entre vida cotidiana e faz-de-conta.Quando um jogo termina, todos os esquemas de ação e pensamento mobilizados em situações de jogo são revertidos, bem como os impactos gerados por ele - quando uma criança é pega numa brincadeira de polícia e ladrão, por exemplo, espera-se que o(a) delinquente não cumpra todos os anos de sua pena comoacontece na vida real. Em outras palavras, na sua acepção clássica, a ideia de círculo mágico expressa uma cláusula que subentende que aquilo que se faz no jogo não deve gerar consequências no restante da vida.

Atualmente, a noção de círculo mágico vem sofrendo inúmeros abalos, dentre os quais, os mais sensíveis envolvem a (des)crença no seu hermetismoem relação ao mundo real. Com o advento e disseminação de tecnologias e práticas culturais que têm acirrado a dissociação entre espaço e tempo ${ }^{17}$, torna-se cada vez menos seguro assegurar a existência de uma hora e um lugar "corretos" para atividades específicas. Nesse cenário, há que se destacar o protagonismo das tecnologias móveis não apenasna afirmação de um status híbrido da corporeidade ${ }^{18}$, mas também como catalisador de transformações no âmbito da ludicidade. Entre os desdobramentos da dissolução daunidade espaço-tempo, está o enfraquecimento do círculo mágico enquanto barreira que separa o jogo e o não-jogo. Ou seja, tais dimensões deixam de ser consideradas como incomunicáveis, uma vez que têm se multiplicado os canais de comunicação entre elas, tornando suas relações cada vez mais porosas e intercambiáveis.

Trata-se de uma conjuntura que descortina uma série de desafios para as relações entre os jogos, as tecnologias e a educação. Sob este pano de fundo, cabe indagar: levando em consideração o embotamento dos limites do círculo mágico, de que maneira o game Pokémon Go tem se comunicado com o mundo real?

Uma das manifestações mais explícitas desse fluxo éa ressignificação das relações entre o indivíduo e o espaço (material e imaterial). Diferente dos jogos digitais tradicionais, os games baseados em realidade aumentada acontecem num cenário que não é inteiramente artificial. Metaforicamente, as telas dos videogames convencionais atuam como portas que, ao serem cruzadasde forma imaginária, introduzem o jogador num mundo inteiramente distinto e apartado em relação àquele do qual acabara de sair. Por outro lado, a função das telas nos jogos de realidade aumentada se assemelha à das lentes, as quais garantem a imersão do jogador no faz-de-conta mediante a alteração de sua percepção do mundo objetivo, mesclando-o com informações digitais e estímulos sensíveis algorítmicos. Em Pokémon Go, é possível observar que os resultados dessa distorção tendem a se converter

16 (HUIZINGA, 2008).

17 (BAUMAN, 2001).

18 (CRUZ JUNIOR; SILVA, 2010). 
na subversão das regras tácitas ou formais pertinentes a cada contexto: praças e esquinas usualmente consideradas perigosas, transformam-se em zonas de lazer e sociabilidade sob a forma de pokestops e ginásios. Evidentemente, essa mudança implica não apenas em novas oportunidades ${ }^{19}$, mas também em problemas sociais e individuais ainda não enfren$\operatorname{tados}^{20}$. De todo o modo, importa destacar que tais jogos podem servir como estímulos à desobediência em relação a protocolos de comportamento hegemônicos, suscitando modos de agir e pensar parcial ou inteiramente originais.

Outro fator digno de menção éa possibilidade de unificar e coordenar ações lúdicas com práticas cotidianas. O colapso do círculo mágicoestá intimamente ligado ao surgimento de novas modalidades lúdicas como os jogos de realidade alternativa ${ }^{21}$ e a gamificação ${ }^{22}$. Em linhas gerais, tais conceitos abraçam não apenas a ideia de que as atividades lúdicas podem transbordar para o restante da vida, mas também que os efeitos desse "vazamento" podem ser canalizados para finalidades sistematicamente determinadas. O poderde colocarindivíduos em movimento e de concentrá-los em lugares específicos fez de Pokémon Go um agente catalisadorde ações específicas no mundo real, como campanhas de doação de sangue e terapias de reabilitação realizadas em hospitais infantis ${ }^{23}$. Essa interação entre jogo e não-jogo significa menosa anulação de um em relação ao outro, do que uma tendência à criação e multiplicação de instâncias de indissociabilidade onde o círculo mágico se funde àillusio ${ }^{24}$.

Os modelos de negócios emergentes na indústria do entretenimento digital também não devem ser perdidos de vista.É importante salientar que o ramo dos jogos digitais vem envidando massivos esforços nointento de expandir e diversificar seu público-consumidor. Entre as principais estratégias empregadas para este fim, estão aquelas que afetam diretamente os princípios norteadores dos games lançados, inclinação esta que tem consagrado títulos dotados de traços como: 1) a possibilidade de serem jogados em sessões curtas e em meio a atividades paralelas; 2) uma curva de aprendizado amigável sustentada por comandos básicos de rápida assimilação; 3) compatibilidade com plataformas versáteis e acessíveis, tais como computadores pessoais, tabletse smartphones. O segmento dos jogos casuais alcunha recebida pelos títulos desse naipe - também generalizou a premissa de que, para atingir a novas audiências, é necessário que seus produtos sejam "gratuitos". No entanto, essa gratuidade precisa ser relativizada, uma vezque costuma levar em consideração apenas

19 Mais detalhes em: http://br.ign.com/pokemon-go/34629/news/5-casos-em-que-pokemon-go-colaborou-com-asociedade

20 Um dos exemplos é a ocorrência de furtos e assaltos a jogadores: http://g1.globo.com/tecnologia/games/ noticia/2016/08/pokemon-go-no-brasil-veja-casos-de-assaltos-com-jogadores.html

21 Mais detalhes em McGonigal (2012).

22 Mais detalhes em Cruz Junior (2014).

$23 \mathrm{http} / /$ www.hypeness.com.br/2016/08/hospital-usa-pokemon-go-pra-incentivar-criancas-internadas-a-sairemdos-seus-quartos/

24 "A illusio é um jogo social levado a sério - fantasia subjetiva coletivamente sancionada, calcada em uma metafísica da distinção, pois para ser o centro do mundo devemos ser reconhecidos como distintos, tendo algum valor, alguma honra e dignidade frente a nós mesmos e aos demais" (OLIVEIRA, 2005, p. 540). 
o momento de aquisição do jogo. O jogador, de fato, não paga para adquirir/baixar e ter acesso às funcionalidades básicas do game. Contudo, para garantir dividendos, as produtoras e desenvolvedoras frequentemente têm se utilizado de sistemas de microtransações, isto é, da prática de comercialização de itens e sistemas VIP no interior do jogo, por intermédio de operações de câmbio que permitem a compra de dinheiro fictício com moedareal. Em Pokemon Go, é possível realizar esse tipo de operação para adquirir as pokecoins, moeda corrente no game, e com isso ter acesso facilitado a itens exclusivos ou que normalmente são obtidos através de levelups e da passagem por pokestops e ginásios.

Apesar de altamente rentável para as indústrias do setor, a implementação e popularização dasmicrotransações e similares têm sido alvo de inúmeras críticas. As principais não se dirigem apenas às implicações práticas desse tipo de operação,mas também aos seus desdobramentos ético-morais. Zagal, Björk e Lewis (2013) chamam atenção para a disseminação do que chamam de "padrões sombrios" no âmbito do design de jogos: modelos usados intencionalmente pelo(s) criador(es) de games para causar experiências negativas aos jogadores, as quais recebem essa classificação por muitas vezes irem contra os interesses do jogador e por constantemente fazerem isso sem o seu consentimento.Uma das principais vertentes dessa tendência é composta pelos padrões sombrios monetários, que em geral consistem em sistemas voltados ao oferecimento - à comercialização - de alternativas para superar interdições e obstáculos artificiais estrategicamente planejados pelos próprios desenvolvedores do game. Em títulos como AngryBirds, por exemplo, o jogador dispõe de um número limitado de chances para tentar vencer cada nível. Caso não tenha sucesso e essas tentativas se esgotem, o jogador deve aguardar um tempo pré-definido para que possam jogar novamente. Caso não queiram esperar, também podemadquirir algumascommodities fornecidas por intermédio das microtransações ${ }^{25}$, entre as quais, estão pacotes de tentativas vendidos a preços variados. Trata-se de uma tática canônica em games do tipo free-to-play (grátis para baixar e jogar), os quais frequentemente recebem a alcunha pejorativa de pay-to-win (pague para vencer).

Ao admitir a aquisição de itens e serviços com dinheiro do mundo real, o desempenho dos jogadores na execução de tarefas passa a não estar subordinado exclusivamente ao seu empenho e dedicação no aprimoramento de habilidades e estratégias. Em outras palavras, tais games nivelam o poder aquisitivo ao esforço individual de um modo que o primeiro é capaz de potencializar o segundo, dando margem a desequilíbrios e assimetrias de performance entre os jogadores.As pokecoins podem ser utilizadas como intermediários na obtenção de itens raros cuja posse pode alterar sensivelmente a experiência de jogo. Em Pokémon Go, as microtransações possibilitam que um indivíduo não só evolua seu personagem duas vezes mais rápido com a ajuda deluckyeggs ${ }^{26}$, mas também que atraia mais pokémons ao seu redor com incenses ${ }^{27}$ e capture-os prescindindo da obrigação de

25 Para maiores detalhes sobre a economia comportamental e os sistemas de gratificação psicológica aplicadas aos games do gênero, ver: https://www.youtube.com/watch? $v=$ B BTGCEFuQw

26 Item que dobra os pontos de experiência obtidos pelo jogador durante meia hora.

27 Item que durante meia hora aumenta a quantidade e variedade de pokémon que adentramazona de alcance do jogador. 
ir às pokestops quando suas pokebolas se esgotarem. Esse fato explicita um paradoxo envolvendo o movimento em Pokémon Go: de um lado, o game é amplamente elogiado por sua eficácia em estimular a realização de atividades físicas e a exploração do mundo exterior; do outro, apresenta mecanismos que ensejam a evolução dos jogadores sem que estesdeem sequer um passo para fora de casa. Em outras palavras, quando alguém adquire pokecoinsestá adquirindo indiretamenteo movimento em sua forma capitalizada: quanto maior a soma investida, menor é a necessidade de romper a inércia.

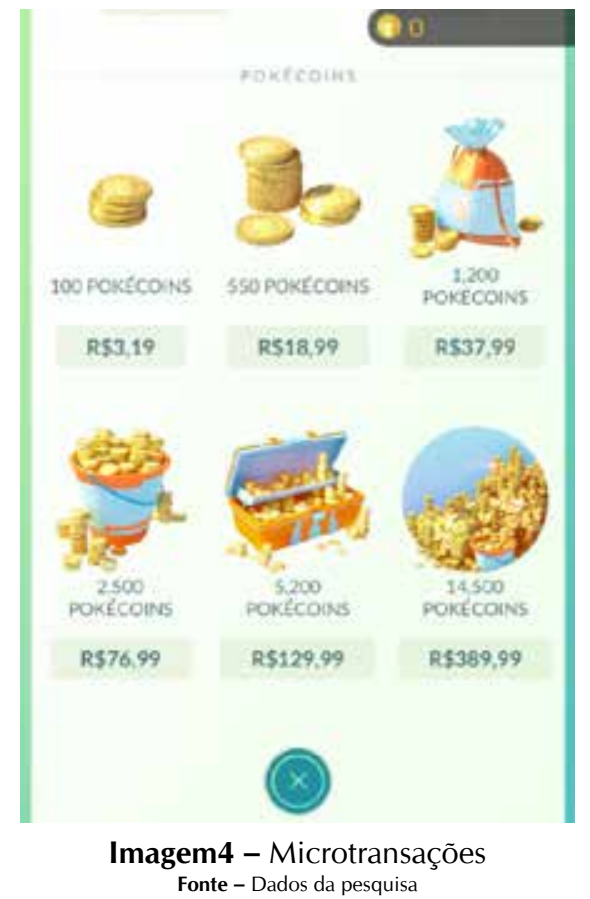

A crescente interpermeabilidade entre jogo e vida cotidiana também tem despertado inquietações de ordem política. Em linhas gerais, preocupa a hipótese de que tais atividades possam atuar como mecanismos de retroalimentação ou mesmo de acirramento de assimetrias de poder e desigualdades sociais(já estabelecidas). O desequilíbrio na distribuição geográfica de pokestops e ginásios, por exemplo,é um dos vários pontos de tensão em Pokémon Go. Na medida em que o game se popularizou, jogadores de várias regiões, sobretudo de contextos rurais e bairros de periferia, questionaram a escassez de pontos de referência que permitissem não apenas o abastecimento de inventários, mas também a possibilidade de estabelecer contato com outros jogadores. Do Capão Redondo ${ }^{28}$ 
aos bairros negros e latinos de Detroit ${ }^{29}$, games como Pokémon Go e o próprio Ingress enfrentam o desafio de lidar com o cada vez mais explícito viés ideológicodas experiências de jogo,dividindo-se entre, de um lado, a revitalização de espaços públicos através desua ocupação e ressignificação, e do outro, a reafirmação de estigmas urbanos e estereótipos sociais que impedem o livre circular dos corpos nas veredas da urbe.

\section{PALAVRAS FINAIS...}

Este não é um texto sobre Pokémon Go. O papel do game na presente exposição foio de fio condutor para a explicitação de princípios emergentes no âmbito dos jogos digitais e das mídias móveis, os quais interpelam o campo educacional de diferentes maneiras. Está em cena o necessário reconhecimento da dimensão formativa dos games (de realidade aumentada), os quais têm atuado como vetores de fomento de novos modos de agir e pensar que, por sua vez, estão intimamente ligados a formas específicas de movimento, fundandoconfigurações próprias para a tríade sujeito-significado-situação. Em contrapartida, a intensificação da intercambialidade entre jogo e vida cotidiana é um precedente que, sob o ponto de vista político, abre-se a toda sorte de interesses, sejam eles voltados à transformação social ou à reprodução do status quo.

Para lidar com essa ambivalência, é fundamental que os sujeitos-jogadores sejam preparados para reivindicar o pleno acesso a experiências lúdico-digitais de lazer, reconhecendo seus aspectos técnicos, estéticos e culturais. Nesse sentido, parece oportuno ressaltar a centralidade das esferas educativas formais e informais, instâncias que podem contribuir não só com a formação de indivíduos aptos ao enfrentamentodos limites e das possibilidades do referido cenário, mas também ao desenvolvimento de projetos e ações específicas orientadas por valores e modelos desvinculados de interesses puramente econômico-mercantis, de modo a contribuir com a diversificação e complexificação das formas de exercício da motricidade mediadas pelas tecnologias digitais.

\section{REFERÊNCIAS}

BAUMAN, Zygmunt. Modernidade Líquida. Rio de Janeiro: Jorge Zahar Ed., 2001

CRUZ JUNIOR, Gilson. Burlando o círculo mágico: o esporte no bojo da gamificação. Movimento, Porto alegre, v. 20, n. 3, p. 941-963, 2014. Disponível em: http://seer. ufrgs.br/index.php/Movimento/article/download/40539/31583. Acesso em: 3. jul. 2016. ; DA SILVA, Erineusa Maria. A (ciber)cultura corporal no contexto da rede: uma leitura sobre os jogos eletrônicos do século XXI. Revista Brasileira de Ciências do Esporte, Florianópolis, v. 32, n. 4, p. 89-104, 2010. Disponível em: http://www. revista.cbce.org.br/index.php/RBCE/article/viewFile/637/592. Acessoem: 2 jul. 2016. 
DIKKERS, Seann. Dewey buys a smartphone. In: DIKKERS, Seann; MARTIN, John; COULTER, Bob (Orgs.). Mobile media learning: amazing uses of mobile devices for learning. Pittsburgh: ETC Press, 2011.

HUIZINGA, Johan. Homo Ludens. São Paulo: Perspectiva, 2008.

JUUL, Jesper. A casual revolution: reinventing video games and their players. Massachusetts: MIT Press, 2010.

KLOPFER, Eric. Foreword/Preface. In: DIKKERS, Seann; MARTIN, John; COULTER, Bob (Orgs.). Mobile media learning: amazing uses of mobile devices for learning. Pittsburgh: ETC Press, 2011.

KUNZ, Elenor. Se-movimentar. In: GONZÁLES, Fernando Jaime; FENSTERSEIFER, Paulo Evaldo (Orgs.). Dicionário crítico da Educação Física. ljuí: Editora Unijuí, 2005.

HUNICKE, Robert; LEBLANC, Marc; ZUBEK, Robert. MDA: a formal approach to game design and game research. In: Proceedings of the Challenges in Game AI Workshop, Nineteenth National Conference on Artificial Intelligence. Anais... 2004.

MARTIN, John et at. When, where, and how: practical considerations when designing your own mobile media learnings. DIKKERS, Seann; MARTIN, John; COULTER, Bob (Orgs.). Mobile media learning: amazing uses of mobile devices for learning. Pittsburgh: ETC Press, 2011.

MCGONIGAL, J. A realidade em jogo: por que os games nos tornam melhores e como eles podem mudar o mundo. Rio de Janeiro: Best Seller, 2012.

OLIVEIRA, Pedro Paulo. Illusio: aquém e além de Bordieu. Mana, Rio de Janeiro, v. 11, n. 2, p 529-543, 2005.

OLWAN, Alex. Unobstrusiveaugmentationofphysicalenvironments: interactiontechniques, spatial displays, andubiquitoussensing. Tese (Doutorado em Ciência da Computação), KTH, 2009.

SCOLARI, Carlos. Narrativas transmedia: cuando todos los médios cuentan.Barcelona: DEUSTO, 2013.

ZAGAL, José; BJÖRK,Staffan; LEWIS, Chris. Dark patterns in the design of games. Proceedings of foundation of Digital Games 2013, Chania, Crete, p. 39-46, 2013.

Recebido em: setembro/2016 Aprovado em: novembro/2016 